\title{
Altitudinal and Spatial Signature of Persistent Organic Pollutants in Soil, Lichen, Conifer Needles, and Bark of the Southeast Tibetan Plateau: Implications for Sources and Environmental Cycling
}

\author{
Ruiqiang Yang, ${ }^{\dagger}$ Shujuan Zhang, ${ }^{\dagger}$ An Li, ${ }^{\dagger}$ Guibin Jiang, ${ }^{\dagger}$ and Chuanyong Jing ${ }^{* \dagger}$ \\ ${ }^{\dagger}$ State Key Laboratory of Environmental Chemistry and Ecotoxicology, Research Center for Eco-Environmental Sciences, Chinese \\ Academy of Sciences, P.O. Box 2871, Beijing 100085, China \\ ${ }^{\ddagger}$ School of Public Health, University of Illinois at Chicago, Chicago, Illinois 60612, United States
}

\section{Supporting Information}

\begin{abstract}
The southeast Tibetan Plateau (TP) of China is characterized by mountain-valley topography and is usually the main channel for the warm and humid airstream from South Asia caused by the Indian monsoon. In this study, it is hypothesized that some semivolatile organic pollutants such as organochlorine pesticides (OCPs) and polycyclic aromatic hydrocarbons (PAHs) can be transported from the densely populated and intensely agricultural Indian Subcontinent via the Indian monsoon and then coldtrapped by the mountains of the southeast TP. Samples of soils, lichens, conifer barks, and needles were collected from five transects to investigate the accumulation patterns of OCPs and PAHs in this region. The OCP concentrations were found to generally increase with increasing altitude in transects 1, 3, and 4, while such trends were insignificant in most cases for PAHs. Total organic carbon/lipid based normalization of concentrations does not strengthen the correlations with altitude in most cases. Chemical concentration ratios in soils of forest areas to clearing sites without forest cover $(\mathrm{F} / \mathrm{C})$ showed significantly positive correlation with $\log K_{\mathrm{oa}}$ and negative correlation with $\log K_{\mathrm{aw}}$ of PAHs, suggesting that the role of forests as a filter and forest soil as a final sink are more pronounced for more lipophilic compounds. A lower $\alpha-/ \gamma-\mathrm{HCH}$ ratio and higher ratios of DDT/DDE and $o, p^{\prime}$-DDT/ $p, p^{\prime}$-DDT compared with the technical products suggest the usage of lindane $(\gamma-\mathrm{HCH})$, DDT, and dicofol in neighboring countries. The suitability of using different sample matrices (soil, lichen, conifer bark, and needles) as passive air samplers in remote regions is evaluated.
\end{abstract}

\section{INTRODUCTION}

Long-range atmospheric transport is the most important pathway for persistent organic pollutants (POPs) to migrate to remote alpine regions. ${ }^{1}$ Similar to the "cold condensation" occurring in high latitude regions, orographic cold trapping in high-altitude areas may remarkably affect the large scale distribution, long-range transport, and long-term fate of persistent organic pollutants (POPs). Since the first report ${ }^{2}$ on the altitude dependence of organochlorine accumulation in mountains in 1998, similar observations have been reported from several alpine regions. ${ }^{3-8}$ In general, the concentrations of relatively volatile POPs on remote mountains tend to increase with an increase in altitude, pointing to the direct input from the atmosphere. However, complications arise from local source emissions, postdeposition degradation, land cover and topography, meteorological conditions, and so forth, as reviewed by Daly and Wania. ${ }^{1}$

Vegetation, including tree leaves, tree barks, lichens, mosses, and so forth, has been used as natural passive air samplers to assess atmospheric pollution and regional/global distribution and transport of POPs. ${ }^{9-14}$ These are particularly valuable for research in remote and poorly accessible areas such as high mountains. ${ }^{15,16}$ Furthermore, large-scale vegetation, for example, forests, may have significant impact on the atmospheric concentration of POPs during the annual growth cycle of the plants. ${ }^{17,18}$ The significance of forests in transferring contaminants from air to soil has also been widely documented. ${ }^{17,19}$ Forest soil receives considerable amounts of pollutants after the annual litter-fall and could be a final sink for POPs from the air.

The Tibetan Plateau (TP) is located in the eastern Eurasian continent, covering approximately one-fourth of the land area of China with a mean altitude of greater than $4000 \mathrm{~m}$ above sea level (a.s.l.). It has long been regarded as one of the most remote and isolated regions in the world. However, the TP is surrounded by the most densely populated and rapidly industrializing countries, including India and China. Some POPs originating from distant source regions have been transported to the plateau and have accumulated due to

Received: August 9, 2013

Revised: October 22, 2013

Accepted: October 28, 2013

Published: October 28, 2013 


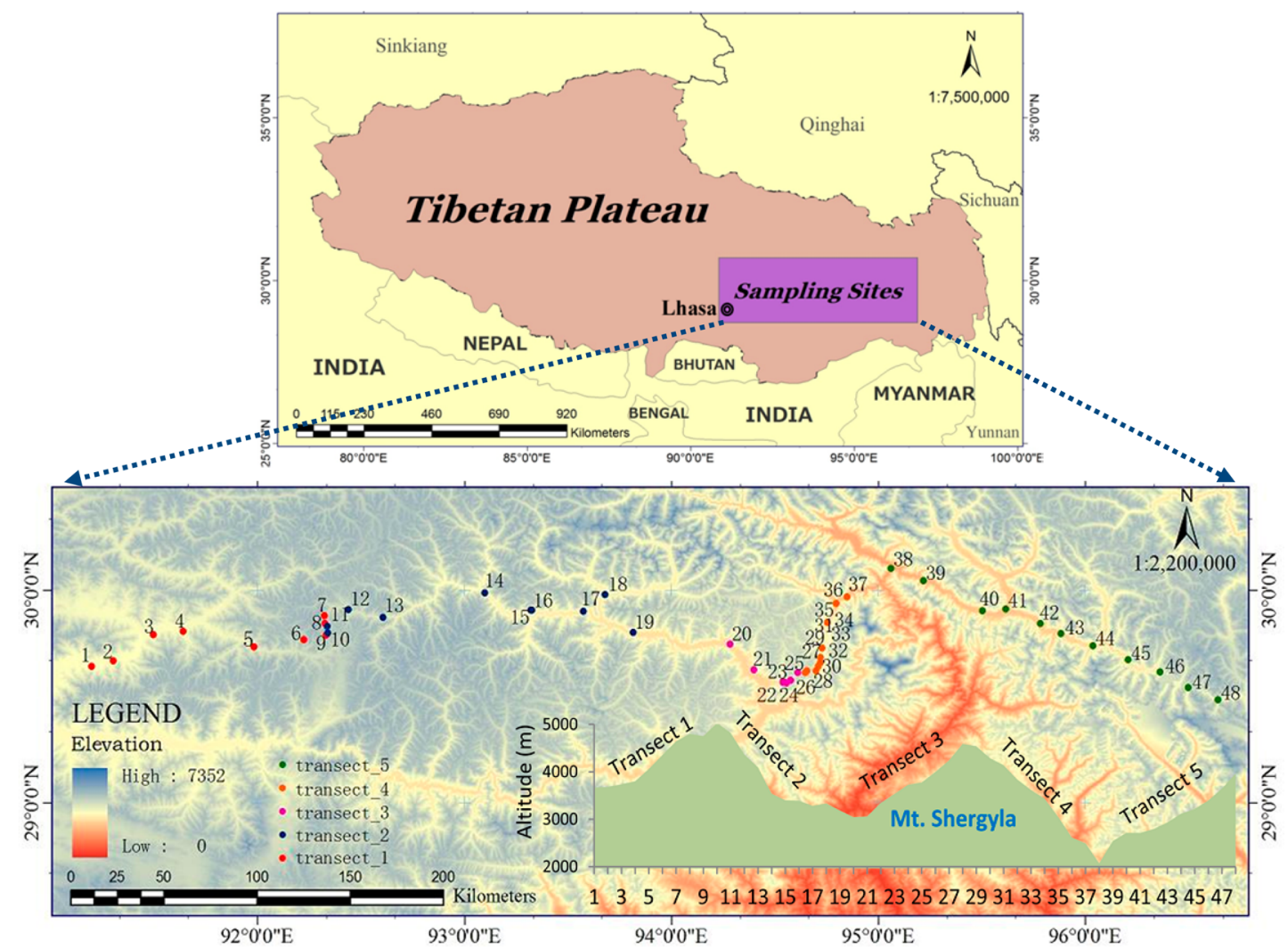

Figure 1. Geographic location and altitude of sampling sites. Numerical information is summarized in the Supporting Information, Table S1.

orographic cold-trapping. Tao et $\mathrm{al}^{20}$ reported the accumulation of organochlorine pesticides (OCPs) and polycyclic aromatic hydrocarbons (PAHs) in soils of the west and northwest TP and believed that the concentrations may represent the background levels of East Asia. Wang et al. ${ }^{8}$ observed that the PAH concentrations and the more volatile OCP concentrations increased with increasing altitude in vegetation in the central Himalayas. In the southeast $\mathrm{TP}$, the transport and fate of pollutants is expected to be influenced by the air mass movement dominated by the Indian monsoon from south Asia. Yang et al. ${ }^{21}$ demonstrated that several OCPs are transported along the valleys from the Indian Subcontinent by the Southern Asian monsoon. Wang et al. ${ }^{22}$ found that POP concentrations in the air from the Indian monsoon-impacted regions are higher than in other regions of the plateau.

The objective of this study was to investigate the altitudinal and spatial signatures of OCPs (HCHs, DDTs, and $\mathrm{HCB}$ ) and $\mathrm{PAHs}$ in southeast Tibet using combined information obtained from analyzing different samples including soils, lichens, conifer barks, and needles. Such a multimatrix approach has not been used previously for study at the TP and was expected to not only serve the major objective of this work but also allow a cross-matrix comparison for their advantages as passive monitors of the geographical distribution of POPs in this remote region. Furthermore, this study aimed to verify the role forests play in delivering pollutants from the atmosphere to soil and to test the hypothesis that forest soils in southeast TP may act as final sinks for the selected POPs.

\section{EXPERIMENTAL SECTION}

Study Area and Sampling. Compared with the western and northern TP regions, the southeast TP is generally lower in elevation, characterized by mountain-valley topography, and contains the densest pristine forests below the tree habitat line. The climate in this region is dominated alternatively by southwest wind in summer and westerly wind in winter. The valleys are usually the main channels for the warm and humid airstream from the Indian Subcontinent to southeast Tibet. ${ }^{23}$ The sampling locations were chosen within Nyingchi Prefecture, where the forest coverage is $46.1 \%$ and ranks third among China's large forested areas. ${ }^{24}$ The vegetation type changes distinctively along the slope of the mountains. From the bottom to the top, there are conifer-broadleaved mixed forest, fir forest, subalpine shrub meadow, alpine glacial drift vegetation, and the snow zone. ${ }^{25}$

All samples were collected in July of 2010 from 48 sites along the 5 transects as shown in Figure 1. Composite needle and bark samples were collected from the same three or four individual conifer trees at each site. Needle samples were taken at heights between 1.5 and $2 \mathrm{~m}$ above the ground from $1.5 \mathrm{yr}$ old branches. Bark pieces were removed from different sides of each tree using a cleaned chisel at a height of $1.5 \mathrm{~m}$ above the ground. At each site, lichen samples were collected from a minimum of six different spots within $30 \mathrm{~m}$ of the tree sampling spot. Surface soil samples $(0-5 \mathrm{~cm})$ were collected using a stainless steel spade. In collecting soils, the layer of fallen leaves, if present, was removed before the sample was taken. Two soil cores (20 cm length and $15 \mathrm{~cm}$ in diameter) were collected using in-house built steel core probes from a forest site and a clearing site without forest cover at transect 4 and sectioned in the field at $2 \mathrm{~cm}$ intervals from the top. All samples were wrapped in aluminum foil, sealed in plastic bags, placed in an iced cooler, and shipped to the laboratory where they were kept at $-20{ }^{\circ} \mathrm{C}$. The total numbers of samples were 98 (including 40 

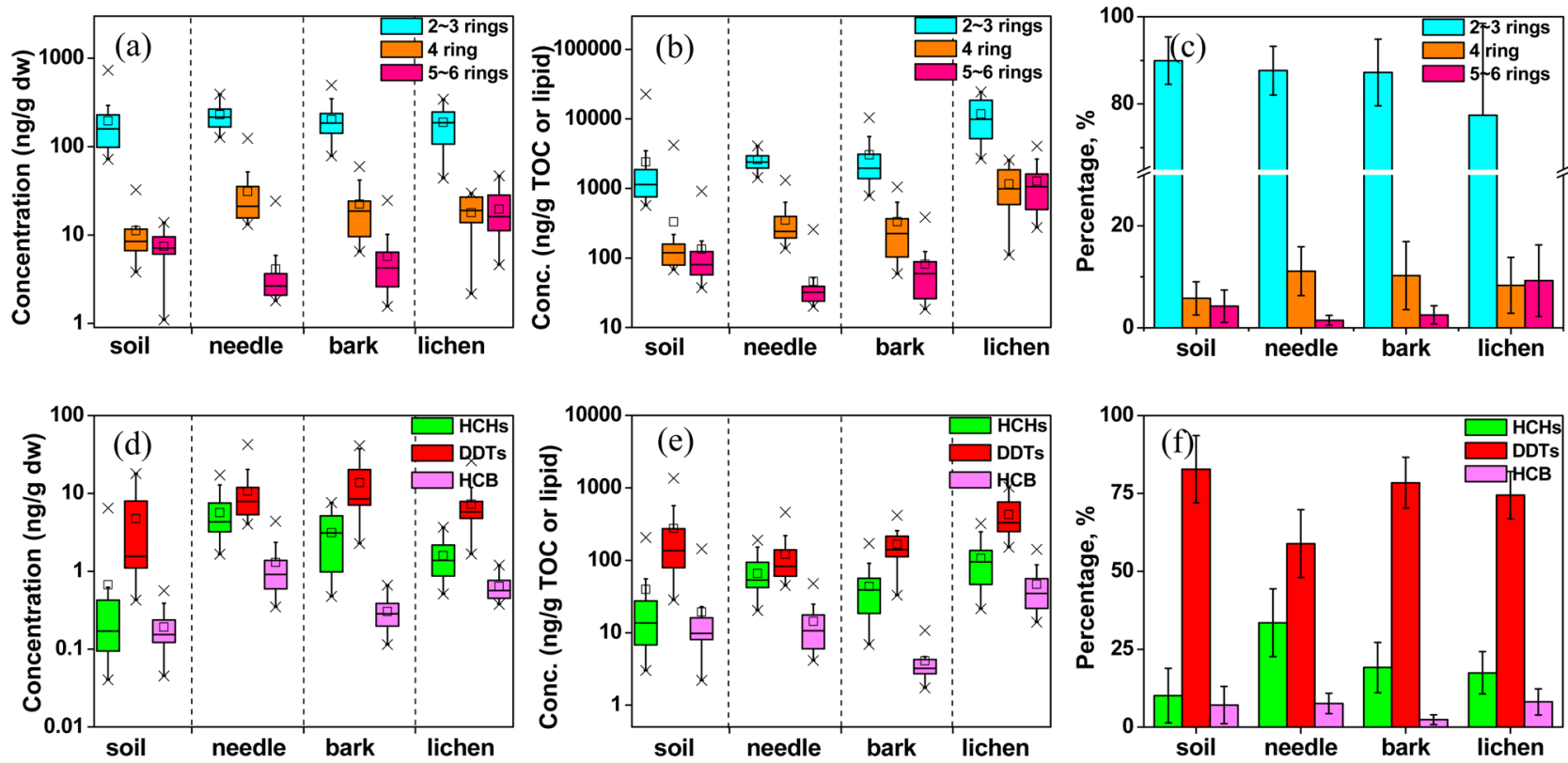

Figure 2. Comparison of PAHs $(a-c)$ and OCPs $(d-f)$ in the four matrices on both dry weight and TOC or lipid weight basis. The box represents the data between the 25th and 75th percentiles. The small box and the horizontal line inside the box indicate the mean and median data. The whiskers above and below the box indicate the 95th and 5th percentiles, and the symbol " $X$ " above and below them represent the outliers. Only data from the 24 sites where all four matrices were collected were used.

soil core segments), 30, 30, and 37 for soil, conifer tree bark, conifer needles, and lichen, respectively.

Chemical Analysis. The details of chemical purchases, sample pretreatment procedures, and methods of instrumental analysis are presented in the Supporting Information, text S1. Briefly, the soil and vegetation samples were freeze-dried, ground or crushed, spiked with chemical surrogates, and extracted by accelerated solvent extraction (ASE) with mixed solvent (hexane/dichloromethane, 1:1, v/v). After rotary evaporation concentration, the extracts were cleaned up by a silica gel/alumina chromatographic column for the analysis of PAH and by a Florisil/acid silica gel column for OCPs. The vegetation extracts for $\mathrm{PAH}$ analysis were further purified using gel permeation chromatography (GPC). The eluents were then concentrated and spiked with injection standards before instrumental analyses.

The instrumental analyses for PAHs and OCPs are described in the Supporting Information, text S1. To analyze PAHs, an Agilent 7890 gas chromatograph (GC) equipped with a J\&W HP-5 ms capillary column $(30 \mathrm{~m} \times 0.25 \mathrm{~mm}$ i.d. $\times 0.25 \mu \mathrm{m}$ film thickness) was used for separation, and an Agilent 5975 mass spectrometer (MS) with an electron ionization (EI) ion source was used for detection. The MS was operated in selective ion monitoring (SIM) mode. For OCP analysis, an Agilent-7890 GC with a ${ }^{63} \mathrm{Ni}$ electron capture detector was used. The samples were run separately using two capillary columns with different polarity (HP-5 and DB-1701). Both columns were $30 \mathrm{~m}$ long and had a $0.25 \mathrm{~mm}$ i.d. and a $0.25 \mu \mathrm{m}$ stationary phase film thickness. Quantification was conducted by the internal standard method.

Quality Control. A procedural blank was run every set of 10 samples to check for interference and cross-contamination during the entire analytical process. The breakdown of DDT was checked daily, and the percentage of the breakdown products was less than $10 \%$. The method detection limits (MDLs) were defined as 3 times of the signal-to-noise value
$(\mathrm{S} / \mathrm{N})$. The MDLs were $0.02-0.91 \mathrm{ng} / \mathrm{g}$ for PAHs, $0.01-0.06$ $\mathrm{ng} / \mathrm{g}$ for $\mathrm{HCH}$ isomers, and $0.07-0.20 \mathrm{ng} / \mathrm{g}$ for DDTs. The average recoveries of spiked surrogates in all samples were 64.1-120.3\% for the five deuterated PAHs, $109.6 \pm 45.9 \%$ for $\operatorname{TCmX}(N=185)$, and $83.1 \pm 14.4 \%(N=185)$ for PCB209. For each type of matrix, two samples were analyzed in duplicate; the average relative percentage differences (RPDs) were in the range $2.4-33.4 \%$ and $2.5-36.6 \%$ for PAHs and OCPs, respectively. The instrument performance was routinely checked using quality control standards.

Total organic carbon (TOC) contents of the soil samples were analyzed by a TOC Analyzer (OI Analytical, USA), and the RPDs of eight duplicated analyses were in the range 2.5$13.0 \%$. The lipid content of the vegetation extracts was determined gravimetrically, and the RPDs of 12 duplicated analyses were in the range $0-10.5 \%$.

\section{RESULTS AND DISCUSSION}

Concentrations of PAHs and OCPs. Summary statistics of the dry-weight-based concentrations of PAHs and OCPs are tabulated in the Supporting Information, Table S3. The concentrations in the four sample matrices are compared in Figure 2. Comparisons with results from other remote areas are presented in the Supporting Information, Table S4.

The average total concentrations of PAHs ( $\left.\sum_{16} \mathrm{PAHs}\right)$ in soil, conifer needle, bark, and lichen samples were $201 \pm 126$, $271 \pm 112,260 \pm 118$, and $253 \pm 89 \mathrm{ng} / \mathrm{g}$, respectively. Low molecular weight PAHs (2-3 rings) were dominant compounds, which accounted for $78-90 \%$ of the total on average in the four matrices (Figure 2c) The mean $\sum_{15} \mathrm{PAH}(104 \mathrm{ng} / \mathrm{g}$, excluding NAP) in the soils of this study approximately doubles that from the northern TP $(51.8 \mathrm{ng} / \mathrm{g}) .{ }^{20}$ On the basis of the means (Supporting Information, Table S3-A), the soil concentration of $\sum_{16} \mathrm{PAH}$ in the present study is similar to those reported from the mountains in western Canada ${ }^{26}$ and Austrian forests, ${ }^{27}$ but $3-5$ times lower than those observed in 


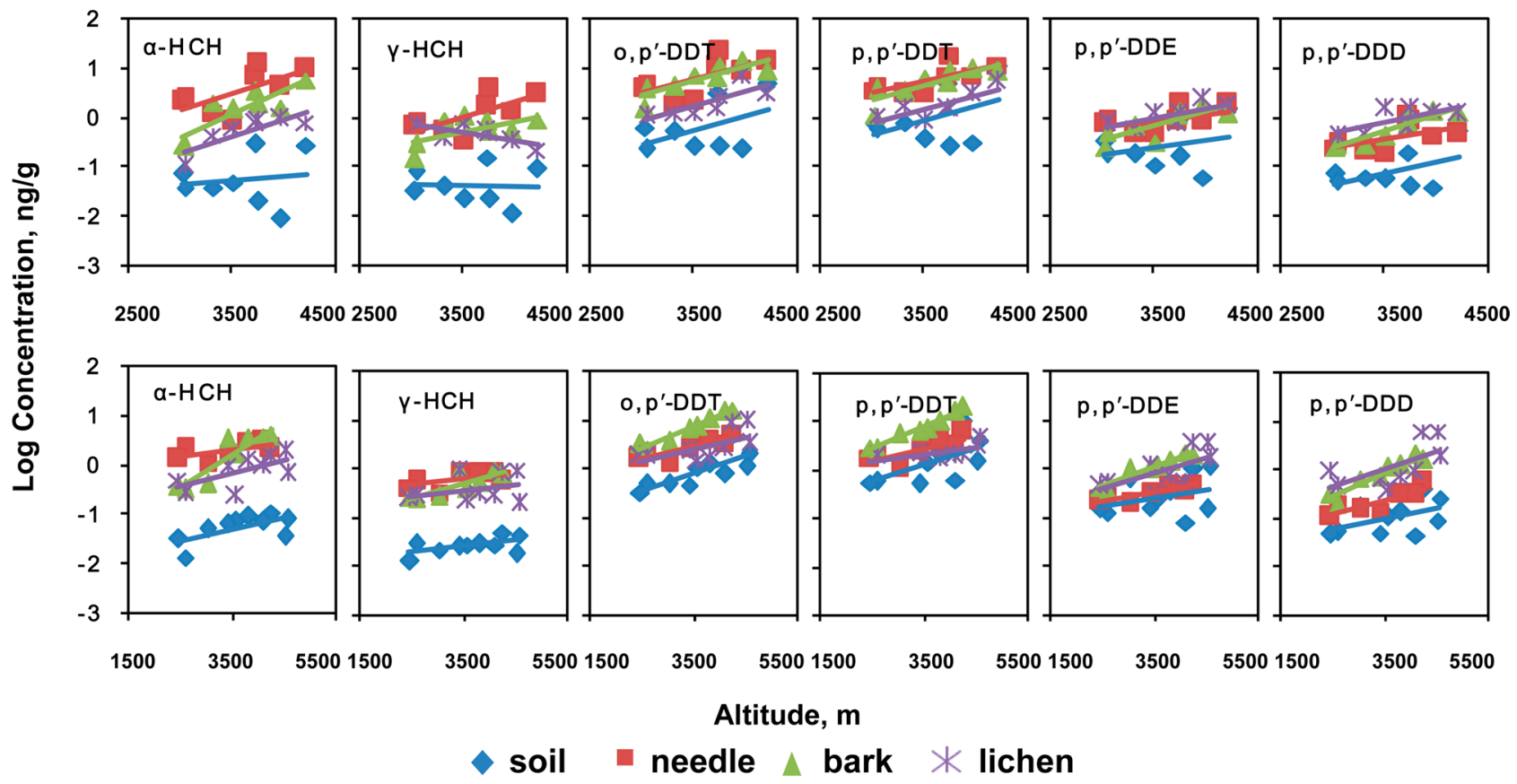

Figure 3. Altitudinal trend of the logarithm concentrations for selected OCPs along transect 3 (top row) and transect 4 (bottom row). Detailed statistics for the linear regressions are given in Table S5 of the Supporting Information.

the Pyrenees and Tatra Mountains of Europe. ${ }^{28}$ PAHs in conifer needles were comparable to those in spruce needles of Austrian forest sites $^{27}$ and the central Himalayas ${ }^{8}$ and lower than those in the Dayton area in the U.S. ${ }^{29}$ Lichen median concentrations of PAHs $(229 \mathrm{ng} / \mathrm{g}$ ) found in this study were about half of those reported in the Pyrenees Mountains. ${ }^{12}$

The average concentrations of $\mathrm{EHCHs}$ in soil, conifer needle, bark, and lichen samples were $0.40 \pm 0.95,5.69 \pm 3.35$, $2.65 \pm 1.98$, and $1.44 \pm 0.89 \mathrm{ng} / \mathrm{g}$, respectively. The corresponding averages of $\sum$ DDTs were $2.85 \pm 4.00,9.73 \pm$ $7.69,11.4 \pm 9.26$, and $7.18 \pm 5.33 \mathrm{ng} / \mathrm{g}$, respectively. The averaged $\sum D D T$ s were about $2-7$ times higher than $\sum \mathrm{HCHs}$ in the corresponding matrices. Compared with those reported in the northern $\mathrm{TP}^{28}$ as well as the Balang Mountain east of the $\mathrm{TP}^{30}$ the concentrations of both HCHs and DDTs found in this study were significantly higher (Supporting Information, Table S3-B), suggesting stronger contribution from the Indian Subcontinent via long-range transport. In comparison with other continents, the concentration range of $\sum \mathrm{HCHs}$ in surface soil was at about the same level as that reported in the western Canadian mountains, ${ }^{3}$ but 1 order of magnitude higher than in the Andossi plateau, Poland. ${ }^{31}$ The concentration of $\sum$ DDTs in soil and vegetation of this study was much higher than those in the European mountains ${ }^{32}$ and western Canadian mountains. ${ }^{3}$ The average concentrations of HCB in soil, conifer needle, bark and lichen were $0.17 \pm 0.10,1.26 \pm 0.92,0.32 \pm$ 0.14 , and $0.64 \pm 0.24 \mathrm{ng} / \mathrm{g}$, respectively. The $\mathrm{HCB}$ concentration in surface soil was comparable to that in the central Alps. ${ }^{31}$

Altitudinal/Spatial Distribution. The regressions of logarithm concentrations against altitude are presented in Figure 3 and the Supporting Information, Figure S1. The equations and statistics of all 210 individual regressions are compiled in the Supporting Information, Table S5, and a summary is in the Supporting Information, Table S6.

For OCPs, statistically significant $\left(R^{2}=0.39-0.96 ; P \leq 0.05\right)$ linear regressions were obtained in most cases for transects 1,3 , and 4 (Supporting Information, Table S5). All matrix-specific median and average regression slopes in the transects are greater than 0 (Supporting Information, Table S6), indicating an increasing trend in OCP concentration with increasing altitude. Particularly notable are the trends along transects 3 and 4 (Figure 3), which constituted the leeward and the windward slopes of Mt. Shergyla, respectively. A closer look found that the regressions for the leeward transect 3 had noticeably weaker statistics than those in the windward transect 4 (Supporting Information, Table S5). This difference was expected because transect 4 lies windward of the summer Indian monsoon along the valley and is more strongly influenced by the air flow than transect 3 . This comparison provides strong evidence that OCPs applied in south Asia are being mobilized by the Indian summer monsoon, experienced long-range atmospheric transport, and are cold-trapped by the mountains of the TP. The diurnal wind pattern (e.g., blowing up-slope when it is warm during the day and down-slope during the night), which is likely to disrupt the general downward deposition of POPs thus weakening the regression against altitude, may have stronger influence on the leeward slope than the windward slope of the mountain. ${ }^{33}$ In addition, precipitation on the windward side is higher than on the leeward side, ${ }^{34}$ and thus, the wet deposition of POPs could be more intensive in transect 4 than in transect 3.

Five frequently detected PAHs were chosen as representative 2-6 ring PAHs, for altitudinal trend analyses (Supporting Information, Figure S1). Only 11 of the 84 regressions were statistically significant $\left(R^{2}=0.57-0.88 ; P \leq 0.05\right)$. However, both the mean and the median regression slopes for the five PAHs were negative (Supporting Information, Table S6), suggesting an overall decreasing trend of dry-weight-based concentrations with increasing altitude. Similar negative correlation between $\mathrm{PAH}$ concentration and altitude was reported in soil samples at Mt. Sagarmatha, Himalayas. ${ }^{35}$ Unlike OCPs, which mainly come to the study area via longrange transport, PAHs may originate also from local 
combustion sources including residential cooking and heating, transportation vehicles, and road construction. ${ }^{36}$ In addition, PAHs, particularly those in the vapor phase, are generally more susceptible to photolysis than OCPs during long-range transport, complicating and weakening the cold-trappingrelated altitudinal trend.

The sampling area stretched over $600 \mathrm{~km}$ from west to east (Figure 1), and the five transects differed considerably. Transects 1 and 2 were closer to a population center of Tibet (Lhasa City) than other transects, and forest coverage was not present (Supporting Information, Table S1). Transect 5 was located at altitude ranging from 2037 to $3917 \mathrm{~m}$, the lowest in elevation among the five transects. No obvious altitudinal gradients were observed in transect 5 for OCPs and PAHs (Supporting Information, Figure S1 and Table S5).

Role Played by TOC/Lipid. The organic carbon contents of all collected samples are included in the Supporting Information, Table S1. The TOC content of the surface soils ranged from $0.16 \%$ to $25.31 \%$ with an average of $6.92 \%$. The soil TOC did not appear to vary with altitude within individual transects, except for transect 1 , where it increased from the west end (low altitude) to the east end (high altitude), as the grass cover increased with the climate changing from dry to wet. The lipid contents of the conifer needle, bark, and lichen samples were $5.24-15.1 \%$ (mean 9.35\%), 1.84-13.8\% (mean 7.43\%), and $0.83-3.61 \%$ (mean $1.70 \%$ ), respectively.

For surface soil samples, all individual OCPs (except for $\beta$ $\mathrm{HCH}$ and $\delta$ - $\mathrm{HCH}$ ) as well as $\sum \mathrm{HCH}$ and $\sum \mathrm{DDT}$ significantly linearly correlate with soil TOC $(P \leq 0.05$; Supporting Information, Figure S2). Similar correlations were also observed for all individual as well as total PAHs $(P \leq 0.05$; Supporting Information, Figure S2). In addition, the correlations tend to be stronger for lighter PAHs (Supporting Information, Figure S2), suggesting that more volatile PAHs are moving into the study area and reaching equilibrium with the soil organic matter compared with the heavier ones. The stronger correlations for the more volatile PAHs are in agreement with the observations that lighter PCBs were more positively correlated with TOC in soils from Norway and the U.K. ${ }^{37}$

Correlations between the lipid contents of needles/lichen and concentrations of PAHs and OCPs were mostly insignificant, while significantly positive in bark samples for $\alpha$-, $\gamma-\mathrm{HCH}$, and the six DDT related compounds, as well as for the $2-3$ ring PAHs and $\sum_{16} \mathrm{PAH}(P<0.05)$. It is interesting that the lipid content of conifer bark samples increases linearly with altitude along all three transects where barks were collected (Supporting Information, Figure S3). This finding is in accordance with the general recognition that lipid storage in biota tends to be higher in low-temperature environments and in agreement with the report that the lipids of pine needles and xylem tissues increase with elevation along individual transects on a global scale. ${ }^{38}$ It is worthwhile to note here that normalization of concentrations based on TOC/lipid did not strengthen the correlations with altitude in most cases, except for PAHs in bark samples along transect 3 where stronger negative correlations were observed.

Comparison among Sample Matrices. The four sample matrices were compared in terms of chemical concentrations before (Figure 2a,d) and after (Figure 2b,e) the normalization of concentrations by TOC/lipid. Lichen, which had lower lipid content (Supporting Information, Table S1), had PAH concentrations 2-3 times higher than other sample matrices based on TOC/lipid, although there was no significant difference in PAHs of 2-4 rings on a dry weight basis among the four matrices. For the HCHs and DDTs, the concentrations were higher in needles and bark based on dry weight (Figure 2d) but higher in lichen based on lipid weight (Figure 2e).

Pearson's correlation of the log-transformed concentrations among the four sample matrices is presented in the Supporting Information, Table S8. The statistically significant pairs include lichen-bark for 3, 5-ring PAHs and needle-bark for 4, 5-ring PAHs on both dry weight and lipid weight bases, and soillichen, bark-liken, and needle-bark for 5-6 ring PAHs on TOC/lipid basis (Supporting Information, Table S8a), suggesting consistency between conifer needles and bark, between lichen and bark, and probably between soil and lichens in indicating $\mathrm{PAH}$ pollution. For OCPs, several pairs of matrices were found to be significantly correlated with each other for HCHs and DDTs on dry weight basis (Supporting Information, Table S8b). Overall, the correlations were not as strong as expected.

Each type of samples has its own physiological structure. The higher capability of lichen in sorbing PAHs and OCPs has little to do with its lipid content, because lichen has the lowest lipid content among the vegetation matrices (Supporting Information, Table S1). With large surface area to volume ratio and a lack of surface cuticle, lichen sorbs all nutrients and contaminants directly from the atmosphere. ${ }^{39}$ The surface adsorption could outweigh lipid absorption, and thus, lichen traps more particulate phase chemicals in dry and wet deposition, which could be responsible for the observed higher fractions of 5-6 ring PAHs in lichen than in other matrices (Figure 2c). In addition, compared with bark and needle samples, lichen is more widespread in the TP regardless of forest coverage. The major drawback is that, although the lifespan of lichen may be as long as 25 years, ${ }^{40}$ the age cannot be easily identified; thus, the exposure time is often unknown.

Tree bark serves as a good passive sampler due to its large surface area and relatively high lipid content and has been used for global/regional scale monitoring of POPs for decades. ${ }^{10}$ Tree bark can accumulate both vapor- and particle-phase contaminants from the atmosphere and reflects contaminant levels over a period of several years. ${ }^{10}$ The lipid content has been used to normalize the measured concentrations. The altitude/climate dependence of lipid content in conifer barks, as observed in this work, should be taken into account when the spatial distribution of POPs is concerned. The surfaces of conifer needles are covered with cuticular wax that accumulates vapor-phase POPs and also traps particulates, ${ }^{4}$ and the age of needles can be easily determined; thus, exposure time is certain. In conclusion, each of the four matrices has its advantages over the others. When used together, they can provide more comprehensive information than when being used alone.

PAHs and OCPs in Soil Cores and Forest Filter Effect. The results obtained from analyzing the two soil cores are presented in the Supporting Information, Figure S4. The two sites are located at the same slope of transect 4 and therefore under the same air mass influence.

For all PAHs and OCPs, there was a general decreasing trend in concentration from the surface to deeper soil layers (Supporting Information, Figure S4). The very low (but higher than the blank and the detection limits) concentration of $\mathrm{HCB}$ $(\sim 0.15 \mathrm{ng} / \mathrm{g} \mathrm{dw})$ observed in the deeper layers suggest the possibility of atmospheric deposition from natural sources and/ or leaching from the top layers. ${ }^{41}$ 
The differences in chemical concentrations between the forest and the clearing lands for OCPs and 4-6 ring PAHs are remarkable. In the forest soil core, the concentrations of $\mathrm{HCB}$, HCHs, DDTs, and $\sum_{4-6 \text { ring }}$ PAHs in the top layer $(0-2 \mathrm{~cm})$ were $1.23,8.95,119$, and $47.8 \mathrm{ng} / \mathrm{g} \mathrm{dw}$, respectively. In contrast, the corresponding concentrations were only 0.43 , $0.47,8.71$, and $13.6 \mathrm{ng} / \mathrm{g} \mathrm{dw}$, respectively, in the clearing site. Similar contrast between forest and adjacent clearing soils was reported for PCDD/Fs. ${ }^{42}$ The soil organic matter content plays a determinant role. The soil TOC was much higher in the forest site (up to $37.3 \%$ ) than in the clearing site (up to $12.3 \%$ ), and in both cores, TOC decreased with increasing depth.

The forest/clearing (F/C) ratio can be viewed as an expression of the "filtering" ability of forests in removing POPs from air compared to the adjacent clearing lands. ${ }^{19}$ In this work, the $\mathrm{F} / \mathrm{C}$ ratio for each chemical was calculated by dividing the concentration in the surface soil from the forest site by that from the clearing site. The $\mathrm{F} / \mathrm{C}$ ratios of individual PAHs were positively correlated with the $\log K_{\mathrm{oa}}$ and negatively correlated with $\log K_{\mathrm{aw}}$ (Figure 4), suggesting that the role of

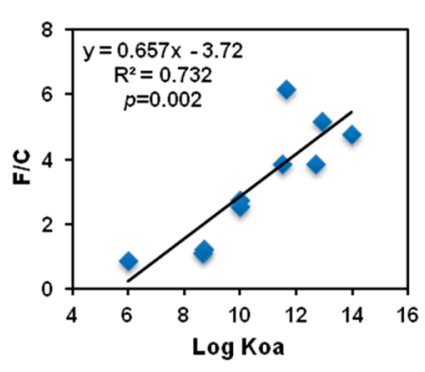

(A)

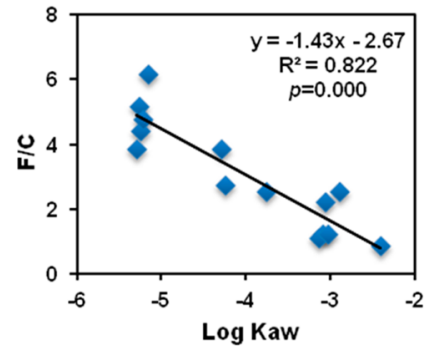

(B)
Figure 4. $\mathrm{F} / \mathrm{C}$ ratio for the needle forest as a function of $\log K_{\mathrm{oa}}(\mathrm{A})$ and $\log K_{\mathrm{aw}}$ (B) of PAHs at $2{ }^{\circ} \mathrm{C}$ (average annual temperature of the sampling sites $\left.{ }^{43}\right)$. The values of $\log K_{\mathrm{oa}}$ and $\log K_{\mathrm{aw}}$ are from the Supporting Information, Table S2.

forests as a filter was more efficient for more lipophilic PAHs. The result underscores the importance of forests in transferring airborne pollutants to soil, suggesting forest soils as a primary sink for less volatile compounds. ${ }^{44}$

Assessment of Sources. Typically, there are two distinct monsoon systems influencing the southeast TP. During summer (June-September), the Indian monsoon induces a supply of air mass over the Indian Subcontinent to move into the mountain ranges of TP, as shown by the surface wind vector in July (Supporting Information, Figure S5a). During winter (November-March), the climate of this region is dominated by westerly airflow (Supporting Information, Figure $\mathrm{S} 5 \mathrm{~b})$. The association of contaminant transport with the climate system in the TP has been investigated in several studies. Wang et al. ${ }^{45}$ observed strong seasonality of OCPs in an ice core from the southern $\mathrm{TP}$, influenced by the India monsoon. More recently, Xiao et al. ${ }^{46}$ and Sheng et al. ${ }^{47}$ reported monsoon-driven variability in the atmospheric input of POPs to the southern TP. The soil concentrations of PAHs and OCPs found in this work were approximately double the levels reported from the northern $\mathrm{TP},{ }^{20}$ which is less impacted by the summer Indian monsoon precipitation than the southeast TP.

$\mathrm{PAH}$ isomer ratios have been widely used as indicators to distinguish different sources in various environmental matrices. $^{29,48}$ The physicochemical properties and degradation potentials are similar between isomers FLT and PYR and between IcdP and BghiP. ${ }^{49,50}$ Thus, their ratios largely retain the original source composition during atmospheric transport and have been suggested to be the most suitable markers to infer petroleum or combustion sources especially in remote areas. ${ }^{50}$ In this study, the measured ratio IcdP/(IcdP + BghiP $)$ was greater than 0.2 , and most of the FLT/(FLT + PYR) values were greater than 0.4 (Supporting Information, Figure S6). On the basis of the source classification by Yunker et al., ${ }^{48}$ the sources of PAHs were mainly from grass, wood, coal, or petroleum combustion.

Isomer ratios of both $\alpha-\mathrm{HCH}$ to $\gamma-\mathrm{HCH}$ and DDT to DDE could indicate possible sources of historical or recent input to the environment. ${ }^{51}$ Technical HCH generally contains $55-80 \%$ of $\alpha-\mathrm{HCH}, 5-14 \%$ of $\beta-\mathrm{HCH}, 8-15 \%$ of $\gamma-\mathrm{HCH}$, and $2-16 \%$ of $\delta$ - $\mathrm{HCH}$, respectively, with the ratio $\alpha-/ \gamma-\mathrm{HCH}$ ranging from 3 to $7 .^{51}$ The average ratios of $\alpha-/ \gamma-\mathrm{HCH}$ in soil, needles, bark, and lichens of the current study were $2.35 \pm 1.32$, $3.61 \pm 1.39$, $2.63 \pm 1.32$, and $1.55 \pm 0.71$, respectively (Supporting Information, Table S9), which were generally lower than the ratios in technical $\mathrm{HCH}$. Considering technical $\mathrm{HCH}$ was heavily used in the past decades while lindane ${ }^{52}(\gamma-\mathrm{HCH})$ is currently being used as a pesticide in surrounding countries such as India, the present low ratio of $\alpha-/ \gamma-\mathrm{HCH}$ indicates the combined source of technical $\mathrm{HCH}$ and lindane. In addition, the ratio of $\alpha-/ \gamma-\mathrm{HCH}$ in bark samples generally increased with altitude along transects 3 and 4 (Supporting Information, Table S10), indicating that higher and colder mountain sites are receiving more aged or more distant $\mathrm{HCHs}$ sources but could also result from different extent of cold trapping for the two isomers. A similar trend was reported in vegetation samples from western Canada. ${ }^{53}$

A low DDT/DDE ratio usually reflects aged sources because DDT can be biodegraded to the more persistent DDE and DDD. The average ratios of $p, p^{\prime}$-DDT/ $p, p^{\prime}$-DDE (Supporting Information, Table S9) in soil, needle, bark, and lichen were $3.97 \pm 2.22,6.40 \pm 1.87,5.81 \pm 1.64$, and $2.72 \pm 1.28$, respectively, which were notably higher than those in vegetation from the western Canada (mean 1.88) ${ }^{53}$ and European mountains $(0.41-1.63){ }^{54}$ The relatively high ratio of DDT to DDE in this study could be attributed to the continued application of parent DDT for disease control in nearby tropical countries. ${ }^{55}$ Furthermore, the average ratios of $o, p^{\prime}$-DDT/ $p, p^{\prime}$-DDT in soil, needles, bark, and lichens were $0.82 \pm 0.36,1.16 \pm 0.25,1.12 \pm 0.24$, and $1.11 \pm 0.68$, respectively (Supporting Information, Table S9), much higher than the ratio in technical DDT (about 0.25). ${ }^{56}$ The pesticide dicofol is characterized by a high ratio of $o, p^{\prime}-\mathrm{DDT}$ to $p, p^{\prime}$ DDT (about 7.0). ${ }^{56}$ The current use of dicofol in regions surrounding the TP (such as India and China) may have contributed to the current DDT profiles.

The accumulations of POPs may impact the alpine ecosystems adversely; for example, declines in amphibian population have been linked to organic pollutants in the Californian Sierra Nevada. ${ }^{57}$ The enrichment of these chemicals also poses health concerns to people relying on the alpine ecosystem for their food supply. Such impacts on the Tibetan Plateau deserve future research. 


\section{ASSOCIATED CONTENT}

\section{S Supporting Information}

Detailed description of laboratory procedures and additional tables and figures from data analysis. This material is available free of charge via the Internet at http://pubs.acs.org.

\section{AUTHOR INFORMATION}

\section{Corresponding Author}

*Phone: +86 106284 9523; fax: +86 106284 9523; e-mail: cyjing@rcees.ac.cn.

\section{Notes}

The authors declare no competing financial interest.

\section{ACKNOWLEDGMENTS}

We thank Dr. Duo Bu from Tibet University for his assistance in sample collection. This work was financially supported by the National Natural Science Foundation of China (41073093, 21277167, and 40873078).

\section{REFERENCES}

(1) Daly, G. L.; Wania, F. Organic contaminants in mountains. Environ. Sci. Technol. 2005, 39 (2), 385-398.

(2) Blais, J. M.; Schindler, D. W.; Muir, D. C. G.; Kimpe, L. E.; Donald, D. B.; Rosenberg, B. Accumulation of persistent organochlorine compounds in mountains of western Canada. Nature 1998, 395 (6702), 585-588.

(3) Daly, G. L.; Lei, Y. D.; Teixeira, C.; Muir, D. C. G.; Wania, F. Pesticides in western Canadian mountain air and soil. Environ. Sci. Technol. 2007, 41 (17), 6020-6025.

(4) Shen, H.; Henkelmann, B.; Levy, W.; Zsolnay, A.; Weiss, P.; Jakobi, G.; Kirchner, M.; Moche, W.; Braun, K.; Schramm, K. W. Altitudinal and chiral signature of persistent organochlorine pesticides in air, soil, and spruce needles (Picea abies) of the Alps. Environ. Sci. Technol. 2008, 43 (7), 2450-2455.

(5) Zheng, X.; Liu, X.; Jiang, G.; Wang, Y.; Zhang, Q.; Cai, Y.; Cong, Z. Distribution of PCBs and PBDEs in soils along the altitudinal gradients of Balang Mountain, the east edge of the Tibetan Plateau. Environ. Pollut. 2012, 161, 101-106.

(6) Yang, R.; Wang, Y.; Li, A.; Zhang, Q.; Jing, C.; Wang, T.; Wang, P.; Li, Y.; Jiang, G. Organochlorine pesticides and PCBs in fish from lakes of the Tibetan Plateau and the implications. Environ. Pollut. 2010, 158 (6), 2310-2316.

(7) Wang, P.; Zhang, Q.; Wang, Y.; Wang, T.; Li, X.; Li, Y.; Ding, L.; Jiang, G. Altitude dependence of polychlorinated biphenyls (PCBs) and polybrominated diphenyl ethers (PBDEs) in surface soil from Tibetan Plateau, China. Chemosphere 2009, 76 (11), 1498-1504.

(8) Wang, X. P.; Yao, T. D.; Cong, Z. Y.; Yan, X. L.; Kang, S. C.; Zhang, Y. Gradient distribution of persistent organic contaminants along northern slope of central-Himalayas, China. Sci. Total Environ. 2006, 372 (1), 193-202.

(9) Howsam, M.; Jones, K. C.; Ineson, P. PAHs associated with the leaves of three deciduous tree species. I - Concentrations and profiles. Environ. Pollut. 2000, 108 (3), 413-424.

(10) Salamova, A.; Hites, R. A. Evaluation of tree bark as a passive atmospheric sampler for flame retardants, $\mathrm{PCBs}$, and organochlorine pesticides. Environ. Sci. Technol. 2010, 44 (16), 6196-6201.

(11) Schrlau, J. E.; Geiser, L.; Hageman, K. J.; Landers, D. H.; Simonich, S. M. Comparison of lichen, conifer needles, passive air sampling devices, and snowpack as passive sampling media to measure semi-volatile organic compounds in remote atmospheres. Environ. Sci. Technol. 2011, 45 (24), 10354-10361.

(12) Blasco, M.; Domeno, C.; Lopez, P.; Nerin, C. Behaviour of different lichen species as biomonitors of air pollution by PAHs in natural ecosystems. J. Environ. Monit. 2011, 13 (9), 2588-2596.
(13) Yogui, G. T.; Sericano, J. Polybrominated diphenyl ether flame retardants in lichens and mosses from King George Island, maritime Antarctica. Chemosphere 2008, 73 (10), 1589-1593.

(14) Salamova, A.; Hites, R. A. Brominated and chlorinated flame retardants in tree bark from around the globe. Environ. Sci. Technol. 2012, 47 (1), 349-354.

(15) Migaszewski, Z. M.; Gałuszka, A.; Pasławski, P. Polynuclear aromatic hydrocarbons, phenols, and trace metals in selected soil profiles and plant bioindicators in the Holy Cross Mountains, SouthCentral Poland. Environ. Int. 2002, 28 (4), 303-313.

(16) Liu, X.; Zhang, G.; Jones, K. C.; Li, X. D.; Peng, X. Z.; Qi, S. H. Compositional fractionation of polycyclic aromatic hydrocarbons (PAHs) in mosses (Hypnum plumaeformae WILS.) from the northern slope of Nanling Mountains, South China. Atmos. Environ. 2005, 39 (30), 5490-5499.

(17) Wania, F.; McLachlan, M. S. Estimating the influence of forests on the overall fate of semivolatile organic compounds using a multimedia fate model. Environ. Sci. Technol. 2001, 35 (3), 582-590.

(18) Gouin, T.; Thomas, G. O.; Cousins, I.; Barber, J.; Mackay, D.; Jones, K. C. Air-surface exchange of polybrominated diphenyl ethers and polychlorinated biphenyls. Environ. Sci. Technol. 2002, 36 (7), $1426-1434$

(19) McLachlan, M. S.; Horstmann, M. Forests as filters of airborne organic pollutants: A model. Environ. Sci. Technol. 1998, 32 (3), 413420.

(20) Tao, S.; Wang, W.; Liu, W.; Zuo, Q.; Wang, X.; Wang, R.; Wang, B.; Shen, G.; Yang, Y.; He, J. S. Polycyclic aromatic hydrocarbons and organochlorine pesticides in surface soils from the Qinghai-Tibetan Plateau. J. Environ. Monit. 2011, 13 (1), 175-181.

(21) Yang, R.; Yao, T.; Xu, B.; Jiang, G.; Zheng, X. Distribution of organochlorine pesticides (OCPs) in conifer needles in the southeast Tibetan Plateau. Environ. Pollut. 2008, 153 (1), 92-100.

(22) Wang, X. P.; Gong, P.; Yao, T. D.; Jones, K. C. Passive air sampling of organochlorine pesticides, polychlorinated biphenyls, and polybrominated diphenyl ethers across the Tibetan Plateau. Environ. Sci. Technol. 2010, 44 (8), 2988-2993.

(23) Yang, S. Y.; Gao, D. Y.; Li, B. S. A preliminary study on the moisture trajectory in the downstream region of Yarlung Zangbo River. Sci. China, Ser. B: Chem. 1987, 8, 893-902.

(24) Guo, Q. Q.; Luo, D. Q.; Fang, J. P.; Lu, J.; Ren, D. Z.; Fu, J. F. Value evaluation of the forest ecosystem service function in the Linzhi area of Tibet. J. Anhui Agric. Sci. 2009, 37 (18), 8746-8749.

(25) Zhao, C. M.; Chen, Q. H.; Qiao, Y. K.; Pan, K. W. Structure and spatial pattern of a natural abies faxoniana population on the eastern edge of Qinghai-Tibetan Plateau. J. Plant Ecol. 2004, 28 (3), 341-350.

(26) Choi, S. D.; Shunthirasingham, C.; Daly, G. L.; Xiao, H.; Lei, Y. D.; Wania, F. Levels of polycyclic aromatic hydrocarbons in Canadian mountain air and soil are controlled by proximity to roads. Environ. Pollut. 2009, 157 (12), 3199-3206.

(27) Weiss, P.; Lorbeer, G.; Scharf, S. Regional aspects and statistical characterisation of the load with semivolatile organic compounds at remote Austrian forest sites. Chemosphere 2000, 40 (9-11), 11591171.

(28) Grimalt, J. O.; van Drooge, B. L.; Ribes, A.; Fernández, P.; Appleby, P. Polycyclic aromatic hydrocarbon composition in soils and sediments of high altitude lakes. Environ. Pollut. 2004, 131 (1), 13-24.

(29) Tomashuk, T. A.; Truong, T. M.; Mantha, M.; McGowin, A. E. Atmospheric polycyclic aromatic hydrocarbon profiles and sources in pine needles and particulate matter in Dayton, Ohio, USA. Atmos. Environ. 2012, 51 (0), 196-202.

(30) Chen, D.; Liu, W.; Liu, X.; Westgate, J. N.; Wania, F. Coldtrapping of persistent organic pollutants in the mountain soils of western Sichuan, China. Environ. Sci. Technol. 2008, 42 (24), 90869091.

(31) Tremolada, P.; Parolini, M.; Binelli, A.; Ballabio, C.; Comolli, R.; Provini, A. Preferential retention of POPs on the northern aspect of mountains. Environ. Pollut. 2009, 157 (12), 3298-3307.

(32) Grimalt, J. O.; van Drooge, B. L.; Ribes, A.; Vilanova, R. M.; Fernandez, P.; Appleby, P. Persistent organochlorine compounds in 
soils and sediments of European high altitude mountain lakes. Chemosphere 2004, 54 (10), 1549-1561.

(33) Lavin, K. S.; Hageman, K. J. Contributions of long-range and regional atmospheric transport on pesticide concentrations along a transect crossing a mountain divide. Environ. Sci. Technol. 2013, 47 (3), 1390-1398.

(34) Du, J.; Gao, R.; Ma, P. F.; Liu, M. Y.; Zhou, K. S. Analysis of stereoscopic climate features on Mt. Seqiha, Tibet. Plateau Mt. Meteorol. Res. 2009, 29 (1), 14-18.

(35) Guzzella, L.; Poma, G.; De Paolis, A.; Roscioli, C.; Viviano, G. Organic persistent toxic substances in soils, waters and sediments along an altitudinal gradient at Mt. Sagarmatha, Himalayas, Nepal. Environ. Pollut. 2011, 159 (10), 2552-2564.

(36) Agarwal, T.; Khillare, P. S.; Shridhar, V.; Ray, S. Pattern, sources and toxic potential of PAHs in the agricultural soils of Delhi, India. J. Hazard. Mater. 2009, 163 (2-3), 1033-1039.

(37) Meijer, S. N.; Steinnes, E.; Ockenden, W. A.; Jones, K. C. Influence of environmental variables on the spatial distribution of PCBs in Norwegian and U.K. soils: Implications for global cycling. Environ. Sci. Technol. 2002, 36 (10), 2146-2153.

(38) Hoch, G.; Korner, C. The carbon charging of pines at the climatic treeline: A global comparison. Oecologia 2003, 135 (1), 1021.

(39) Muir, D. C. G.; Segstro, M. D.; Welbourn, P. M.; Toom, D.; Eisenreich, S. J.; Macdonald, C. R.; Whelpdale, D. M. Patterns of accumulation of airborne organochlorine contaminants in lichens from the upper great lakes region of Ontario. Environ. Sci. Technol. 1993, 27 (6), 1201-1210.

(40) Ockenden, W. A.; Steinnes, E.; Parker, C.; Jones, K. C. Observations on persistent organic pollutants in plants: Implications for their use as passive air samplers and for POP cycling. Environ. Sci. Technol. 1998, 32 (18), 2721-2726.

(41) Bailey, R. E. Global hexachlorobenzene emissions. Chemosphere 2001, 43 (2), 167-182.

(42) Hassanin, A.; Lee, R. G. M.; Steinnes, E.; Jones, K. C. PCDD/Fs in Norwegian and U.K. soils: Implications for sources and environmental cycling. Environ. Sci. Technol. 2005, 39 (13), 4784-4792.

(43) Wang, Y. J.; Ma, Y. M.; Zhu, Z. K.; Li, M. S. Variation characteristics of meteorological elements in near surface layer over the Lulang Valley of Southeastern Tibetan Plateau. Plateau Meteorol. 2010, 29 (1), 63-69.

(44) Weiss, P. Vegetation/soil distribution of semivolatile organic compounds in relation to their physicochemical properties. Environ. Sci. Technol. 2000, 34 (9), 1707-1714.

(45) Wang, X. P.; Yao, T. D.; Wang, P. L.; Wei, Y.; Tian, L. D. The recent deposition of persistent organic pollutants and mercury to the Dasuopu glacier, Mt. Xixiabangma, central Himalayas. Sci. Total Environ. 2008, 394 (1), 134-43.

(46) Xiao, H.; Shen, L.; Su, Y.; Barresi, E.; DeJong, M.; Hung, H.; Lei, Y. D.; Wania, F.; Reiner, E. J.; Sverko, E.; Kang, S. C. Atmospheric concentrations of halogenated flame retardants at two remote locations: The Canadian high Arctic and the Tibetan Plateau. Environ. Pollut. 2012, 161 (0), 154-161.

(47) Sheng, J.; Wang, X.; Gong, P.; Joswiak, D. R.; Tian, L.; Yao, T.; Jones, K. C. Monsoon-driven transport of organochlorine pesticides and polychlorinated biphenyls to the Tibetan Plateau: Three year atmospheric monitoring study. Environ. Sci. Technol. 2013, 47 (7), 3199-3208.

(48) Yunker, M. B.; Macdonald, R. W.; Vingarzan, R.; Mitchell, R. H.; Goyette, D.; Sylvestre, S. PAHs in the Fraser River basin: A critical appraisal of $\mathrm{PAH}$ ratios as indicators of $\mathrm{PAH}$ source and composition. Org. Geochem. 2002, 33 (4), 489-515.

(49) Behymer, T. D.; Hites, R. A. Photolysis of polycyclic aromatic hydrocarbons adsorbed on fly ash. Environ. Sci. Technol. 1988, 22 (11), $1311-1319$.

(50) Ding, X.; Wang, X. M.; Xie, Z. Q.; Xiang, C. H.; Mai, B. X.; Sun, L. G.; Zheng, M.; Sheng, G. Y.; Fu, J. M.; Pöschl, U. Atmospheric polycyclic aromatic hydrocarbons observed over the North Pacific
Ocean and the Arctic area: Spatial distribution and source identification. Atmos. Environ. 2007, 41 (10), 2061-2072.

(51) Willett, K. L.; Ulrich, E. M.; Hites, R. A. Differential toxicity and environmental fates of hexachlorocyclohexane isomers. Environ. Sci. Technol. 1998, 32 (15), 2197-2207.

(52) Li, Y. F.; Macdonald, R. W. Sources and pathways of selected organochlorine pesticides to the Arctic and the effect of pathway divergence on $\mathrm{HCH}$ trends in biota: A review. Sci. Total Environ. 2005, $342(1-3), 87-106$.

(53) Davidson, D. A.; Wilkinson, A. C.; Blais, J. M.; Kimpe, L. E.; McDonald, K. M.; Schindler, D. W. Orographic cold-trapping of persistent organic pollutants by vegetation in mountains of Western Canada. Environ. Sci. Technol. 2002, 37 (2), 209-215.

(54) Calamari, D.; Tremolada, P.; Di Guardo, A.; Vighi, M. Chlorinated hydrocarbons in pine needles in Europe: Fingerprint for the past and recent use. Environ. Sci. Technol. 1994, 28 (3), 429-434.

(55) Zhang, G.; Chakraborty, P.; Li, J.; Sampathkumar, P.; Balasubramanian, T.; Kathiresan, K.; Takahashi, S.; Subramanian, A.; Tanabe, S.; Jones, K. C. Passive atmospheric sampling of organochlorine pesticides, polychlorinated biphenyls, and polybrominated diphenyl ethers in urban, rural, and wetland sites along the coastal length of India. Environ. Sci. Technol. 2008, 42 (22), 8218-8223.

(56) Qiu, X.; Zhu, T.; Yao, B.; Hu, J.; Hu, S. Contribution of dicofol to the current DDT pollution in China. Environ. Sci. Technol. 2005, 39 (12), 4385-4390.

(57) Sparling, D. W.; Fellers, G. M.; McConnell, L. L. Pesticides and amphibian population declines in California, USA. Environ. Toxicol. Chem. 2001, 20 (7), 1591-1595. 